\title{
Neutrophil Percentage and Neutrophil-to-Monocyte Ratio as Independent Risk Factors in the Severity of COVID-19
}

\section{Fei Peng}

Second Xiangya Hospital

Si Lei

Second Xiangya Hospital

Chenfang Wu

Second Xiangya Hospital

Bo Yu

Second Xiangya Hospital

Yanjun Zhong

Second Xiangya Hospital

Shangjie Wu ( $\nabla$ wushangjie@csu.edu.cn )

The Second Xiangya Hospital, Central South University

\section{Research Article}

Keywords: COVID-19, neutrophil percentage, neutrophil-to-monocyte ratio

Posted Date: August 6th, 2020

DOI: https://doi.org/10.21203/rs.3.rs-52622/v1

License: (c) (1) This work is licensed under a Creative Commons Attribution 4.0 International License. Read Full License 


\section{Abstract}

\section{Background}

Inflammation plays an important role in progression of the various viral pneumonia containing COVID-19, severe inflammatory responses could lead to an imbalance of immune response. The purpose of this study was to explore the possibility of the white blood count, neutrophil percentage, neutrophil-tomonocyte ratio (NMR) and neutrophil-to-lymphocyte ratio (NLR) at admission to reflect the clinical severity in patients with COVID-19.

\section{Methods}

Clinical and laboratory data of adult COVID-19 patients in Changsha, China, were collected and analyzed on admission. A logistic regression model was adopted to analyze the association between the disease severity and related risk factors. The receiver operating characteristic (ROC) curve was utilized to analyze the abilities of potential risk factors in the prediction of COVID-19 severity.

\section{Results}

Compared with non-severe patients, the severe ones had significantly higher levels of neutrophil percentage (74.9\% vs. $62.1 \%$; $P$ < 0.001), NLR (4.1 vs. $2.1 ; P<0.001)$ and NMR (12.4 vs. 8.0; $P<0.001)$. A regression analysis showed that neutrophil percentage $(\mathrm{OR}, 1.113 ; 95 \% \mathrm{Cl}, 1.020-1.213 ; \mathrm{P}=0.016)$ and NMR (OR, 1.110; 95\% Cl, 1.002-1.230; P = 0.046) were significantly associated with severity of COVID-19 patients. ROC curve showed that the area under the curves of neutrophil percentage, NMR and the combination of them were 0.842 (95\% confidence interval (Cl), 0.782-0.902), $0.790(95 \% \mathrm{Cl}, 0.710-0.871)$ and $0.851(95 \% \mathrm{Cl}, 0.790-0.911)$, respectively.

\section{Conclusions}

Neutrophil percentage and NMR may act as independent risk factors in the severity of COVID-19.

\section{Background}

To our knowledge, coronavirus disease 2019 (COVID-19) is a disease caused by severe acute respiratory syndrome coronavirus 2 (SARS-CoV-2) [1], which broke out firstly in December 2019, Wuhan, China[2, 3] and spread rapidly around the world. SARS-CoV-2 is the seventh member of coronaviruses family and can be transmitted from person to person [4,5]. As of July 31, 2020, nearly 88122 people were diagnosed and 4668 people died from COVID-19 in China[6], and more than seventeen million cases as well as 680000 deaths have been identified across the world [7].

Generally speaking, the manifestations of COVID-19 are typically mild or moderate, but it can also contribute to severe illness especially progress rapidly to dyspnea, acute respiratory failure or even death[8]. There is mounting evidence that inflammation plays an important role in progression of the 
various viral pneumonia containing COVID-19[9, 10]. Severe inflammatory responses could lead to an imbalance of immune response. Therefore, if early identifications and interventions can be taken in time through recognizing the warning signals of severe COVID-19, it is possible to boost cure rate, reduce mortality and shorten length of hospital stay. White blood cell count, neutrophil percentage, neutrophil-tomonocyte ratio (NMR) and neutrophil-to-lymphocyte ratio (NLR) are good biomarkers for inflammation and immune status in vivo, which are also simple, reproducible and cost-effective[11-18]. Given this situation, we wondered if these parameters at admission could help reflect the clinical severity in patients with COVID-19.

\section{Methods}

Study Design and Participants

This case series was subjected to approval by the institutional ethics board of the Second Xiangya Hospital of Central South University (No. 2020001). Laboratory-confirmed adult COVID-19 patients using real-time polymerase chain reaction admitted to the Public Health Treatment Center of Changsha, China, by March 14th 2020, were retrospectively collected and enrolled using the following inclusion criteria: 1) $\geq 18$ years old; 2) Without disease history of blood system. Additional informed consent was obtained from all patients for which identifying information is included in this article.

\section{Data Collection}

Two members of our team carefully collected and reviewed the medical records of patients individually. The detailed information on demographic data, underlying comorbidities, medical history, symptoms, blood test parameters, and chest computed tomography (CT) scans on admission were recorded. The date of disease onset was defined as the day when the symptoms was noticed. We used one of the following criteria to determine severe cases of COVID-19: 1) respiratory rate $\geq 30 / \mathrm{min} ; 2$ ) oxygen saturation $\leq 93 \%$; 3) $\mathrm{PaO} 2 / \mathrm{FiO} 2 \leq 300 \mathrm{mmHg}$; 4) lung lesions progressed $>50 \%$ within $24-48$ hours; 5) mechanical ventilation was implemented; 6) shock; 7) intensive care unit admission.

\section{Statistical Analysis}

Because all continuous variables in our study were non-normally distributed, we used median with range and the Mann-Whitney test to depict and analyze them. The $\chi^{2}$ test or Fisher exact test was utilized to compare differences for categorical variables. Univariate analyses were carried out using a logistic regression model to analyze the association between the disease severity of COVID-19 and related factors. Multivariate linear regression was used to analyze the correlation between multiple variables (gender, age, neutrophil percentage, NMR, NLR, chest CT with ground glass change, hypertension, cardiovascular disease) and the severity of COVID-19. Areas under the curve (AUCs) with $95 \%$ confidence intervals (Cls) were computed to assess the severity of COVID-19 using potential predictors; AUC $>0.70$ was considered clinically relevant. All analyses were performed using IBM SPSS, version 26. 


\section{Results}

Baseline characteristics of the participants were summarized in Table 1. A total of 220 adult patients with laboratory-confirmed COVID-19 without histories of blood system were included in our study; 40 patients (18.2\%) progressed to severe cases. Males were more likely to have severe COVID-19 (65.0\% vs. 35.0\%, P $=0.042)$. Compared to non-severe patients, the severe ones were older (57 years vs. 41 years, $P<0.001)$. The virus shedding time ( 21 days vs. 15 days, $P=0.001$ ) and the duration of hospitalization ( 21 days vs. 17 days, $P=0.002$ ) were both significantly longer in severe patients than non-severe cases. With regard to comorbidities, hypertension ( $35.0 \%$ vs. $13.3 \% ; \mathrm{P}=0.001)$ and cardiovascular disease $(12.5 \%$ vs $2.8 \% ; \mathrm{P}=$ 0.020 ) were more common in severe cases. They also showed higher ratios of several symptoms than non-severe cases, including fever $(90.0 \%$ vs. $62.8 \%$; $P<0.001)$, fatigue $(70.0 \%$ vs. $38.9 \% ; P<0.001)$, anorexia (65.0\% vs. $47.2 \%$; $P=0.042)$, chills $(25.0 \%$ vs. $9.4 \% ; P=0.014)$, myalgia $(20.0 \%$ vs. $8.3 \% ; P=$ $0.043)$, dyspnea ( $90.0 \%$ vs. $21.1 \% ; P=0.001)$, expectoration ( $62.5 \%$ vs. $42.8 \% ; P=0.024)$, and hemoptysis (10.0\% vs. $2.2 \% ; \mathrm{P}=0.038)$. In addition, chest $\mathrm{CT}$ with ground glass change was more common in severe cases $(75.0 \%$ vs. $43.3 \% ; P<0.001)$.

Neutrophil percentage (74.9\% vs. $62.1 \%$; $P<0.001)$, NLR (4.1 vs. $2.1 ; \mathrm{P}<0.001)$ and NMR (12.4 vs. 8.0; $P<$ 0.001 ) were significantly increased in severe COVID-19, whereas the white blood cell count did not show any statistically significant difference $(P=0.521)$. (Table 2$)$

In the univariate analysis, the severity was associated with gender (odds ratio [OR], $0.482 ; 95 \% \mathrm{Cl}, 0.236-$ $0.982 ; \mathrm{P}=0.045)$, age $(\mathrm{OR}, 1.046 ; 95 \% \mathrm{Cl}, 1.021-1.071 ; \mathrm{P}<0.001)$, hypertension $(\mathrm{OR}, 0.286 ; 95 \% \mathrm{Cl}$, $0.131-0.623 ; \mathrm{P}=0.002)$, cardiovascular disease $(\mathrm{OR}, 0.200 ; 95 \% \mathrm{Cl}, 0.055-0.728 ; \mathrm{P}=0.015)$, neutrophil percentage (OR, 1.168; 95\% Cl, 1.110-1.228; $\mathrm{P}<0.001)$, NLR (OR, 1.773; 95\% Cl, 1.424-2.207; $\mathrm{P}<0.001)$, NMR (OR, 1.253; 95\% Cl, 1.151-1.363; P<0.001) ( Table 3). However, in multivariate analysis, only neutrophil percentage $(\mathrm{OR}, 1.113 ; 95 \% \mathrm{Cl}, 1.020-1.213 ; \mathrm{P}=0.016)$ and $\mathrm{NMR}(\mathrm{OR}, 1.110 ; 95 \% \mathrm{Cl}, 1.002-$ 1.230; $P=0.046$ ) were found to be independent risk factors for the severe COVID-19. (Table 4)

Receiver operating characteristics (ROC) analysis showed that neutrophil percentage, NMR and the combination of them were able to predict the severity of COVID-19 ( $P<0.001$ for all). The AUC of neutrophil percentage, NMR and the combination were $0.842(95 \% \mathrm{Cl}, 0.782-0.902), 0.790(95 \% \mathrm{Cl}$, $0.710-0.871$ ), and 0.851 ( $95 \% \mathrm{Cl}, 0.790-0.911)$, respectively. The optimum cutoffs were $49.7 \%, 45.3 \%$, and $53.6 \%$, respectively. The sensitivities were $92.5 \%, 57.5 \%$ and $72.5 \%$, respectively, and the specificity was $57.3 \%, 87.8 \%$, and $81.2 \%$ respectively. (Table 5 ) 
Table 1

Comparison of general data between the patients in non-severe group and severe group

\begin{tabular}{|c|c|c|c|}
\hline & $\begin{array}{l}\text { Severe } \\
(n=40)\end{array}$ & Non-severe $(n=180)$ & P Value \\
\hline Sex & $26 / 40$ & $84 / 180$ & 0.042 \\
\hline Male & $14 / 40$ & $96 / 180$ & \\
\hline \multicolumn{4}{|l|}{ Female } \\
\hline Age, years & $57(45,66)$ & $41(34,54)$ & 0.000 \\
\hline \multicolumn{4}{|l|}{ Comorbidity } \\
\hline Hypertension, \% & $14(35.0)$ & $24(13.3)$ & 0.001 \\
\hline Cardiovascular disease, $\%$ & $5(12.5)$ & $5(2.8)$ & 0.020 \\
\hline Diabetes, \% & $3(1.7)$ & $13(32.5)$ & 1.000 \\
\hline Cerebrovascular disease, \% & $1(0.6)$ & $2(5.0)$ & 0.454 \\
\hline Digestive system disease, \% & $2(1.1)$ & $16(40.0)$ & 0.539 \\
\hline Respiratory system disease, \% & $3(1.7)$ & $7(17.5)$ & 0.394 \\
\hline Endocrine system disease, \% & $2(1.1)$ & $5(12.5)$ & 0.614 \\
\hline No signs and symptoms, \% & $0(0.0)$ & $17(9.4)$ & 0.047 \\
\hline \multicolumn{4}{|l|}{ Symptoms } \\
\hline Fever, \% & $36(90.0)$ & $113(62.8)$ & $<0.001$ \\
\hline Fatigue, \% & $28(70.0)$ & $70(38.9)$ & $<0.001$ \\
\hline Cough, \% & $27(67.5)$ & $167(92.8)$ & 0.132 \\
\hline Anorexia, \% & $26(65.0)$ & $85(47.2)$ & 0.042 \\
\hline Chills, \% & $10(25.0)$ & $17(9.4)$ & 0.014 \\
\hline Myalgia, \% & $8(20.0)$ & $15(8.3)$ & 0.043 \\
\hline Dyspnea, \% & $36(90.0)$ & $38(21.1)$ & 0.001 \\
\hline Expectoration, \% & $25(62.5)$ & $77(42.8)$ & 0.024 \\
\hline Pharyngalgia, \% & $3(7.5)$ & 31 (17.2) & 0.124 \\
\hline Diarrhea, \% & $6(15.0)$ & $44(24.4)$ & 0.197 \\
\hline
\end{tabular}

Abbreviation: CT, computed tomography; NLR, neutrophil/ lymphocyte ratio; NMR, neutrophil/ monocyte ratio. 


\begin{tabular}{|c|c|c|c|}
\hline & $\begin{array}{l}\text { Severe } \\
(n=40)\end{array}$ & Non-severe $(n=180)$ & P Value \\
\hline Hemoptysis, \% & $4(10.0)$ & $4(2.2)$ & 0.038 \\
\hline Dizziness, \% & $5(12.5)$ & $20(11.1)$ & 0.785 \\
\hline Headache, \% & $9(22.5)$ & $21(11.7)$ & 0.071 \\
\hline Vomiting, \% & $6(15.0)$ & $18(10.0)$ & 0.400 \\
\hline Abdominal pain, $\%$ & $2(5.0)$ & $7(9)$ & 0.669 \\
\hline Nausea, \% & $4(10.0)$ & $25(13.9)$ & 0.511 \\
\hline Chest CT positive rate, $\%$ & $40(100.0)$ & 169 (93.9) & 0.222 \\
\hline $\begin{array}{l}\text { Chest CT with ground } \\
\text { glass change, } \%\end{array}$ & $30(75.0)$ & $78(43.3)$ & $<0.001$ \\
\hline Virus shedding time, days & $21(16,32)$ & $17(13,24)$ & 0.002 \\
\hline Duration of hospitalization, days & $21(14,32)$ & $15(11,23)$ & 0.001 \\
\hline
\end{tabular}

$P$ values indicate differences between severe and non-severe COVID-19 patients. $P<0.05$ was considered statistically significant. Continuous variables were described as median with range and analyzed by Mann-Whitney test. Categorical variables were described as percentages and analyzed by the $\chi^{2}$ test or Fisher exact test.

Table 2

Blood test parameters of patients with COVID-19 on admission.

\begin{tabular}{|lllll|}
\hline & Normal Range & $\begin{array}{l}\text { Severe } \\
(\mathbf{n}=\mathbf{4 0})\end{array}$ & $\begin{array}{l}\text { Non-severe } \\
(\mathbf{n}=180)\end{array}$ & P Value \\
\hline White blood cell count, $\times 10^{9} / \mathrm{L}$ & $3.5-9.5$ & $4.8(3.3-6.5)$ & $4.5(3.6-5.6)$ & 0.521 \\
\hline Neutrophil percentage, \% & $40-75$ & $74.9(68.0-83.1)$ & $62.1(55.6-68.4)$ & $<0.001$ \\
\hline NLR & $/$ & $4.1(3.0-7.0)$ & $2.1(1.6-3.0)$ & $<0.001$ \\
\hline NMR & $/$ & $12.4(8.9-22.5)$ & $8.0(6.1-10.0)$ & $<0.001$ \\
\hline Abbreviation: NLR, neutrophil/ lymphocyte ratio; NMR, neutrophil/ monocyte ratio. & \\
\hline $\begin{array}{l}\text { P values indicate differences between non-severe COVID-19 patients and severe CoVID-19 patients. P } \\
<0.05 \text { was considered statistically significant. Continuous variables were described as median with } \\
\text { range and analyzed by Mann-Whitney test. }\end{array}$ & & \\
\hline
\end{tabular}


Table 3

Univariate analysis of factors related to the severity of COVID-19 patients

\begin{tabular}{|lll|}
\hline Variables & Odds Ratio $(95 \%$ Cl) & P Value \\
\hline Gender & $0.482(0.236-0.982)$ & 0.045 \\
\hline Age & $1.046(1.021-1.071)$ & $<0.001$ \\
\hline White blood cell count & $1.108(0.903-1.360)$ & 0.325 \\
\hline Neutrophil percentage & $1.168(1.110-1.228)$ & $<0.001$ \\
\hline NLR & $1.773(1.424-2.207)$ & $<0.001$ \\
\hline NMR & $1.253(1.151-1.363)$ & $<0.001$ \\
\hline Hypertension & $0.286(0.131-0.623)$ & 0.002 \\
\hline Cardiovascular disease & $0.200(0.055-0.728)$ & 0.015 \\
\hline Chest CT with ground glass change & $0.255(0.118-0.553)$ & 0.001 \\
\hline Univariate analysis was carried out using a logistic regression model. & \\
\hline $\begin{array}{l}\text { Abbreviation: Cl, confidence interval; NLR, neutrophil/ lymphocyte ratio; NMR, neutrophil/ monocyte } \\
\text { ratio. }\end{array}$ & \\
\hline P<0.05 was considered statistically significant. & \\
\hline
\end{tabular}


Table 4

Multivariate analysis of factors related to the severity of COVID-19 patients

\begin{tabular}{|lcccccc|}
\hline & B & SE & Wald & P & OR & 95\% Cl \\
\hline Gender & 0.796 & 0.462 & 2.963 & 0.085 & 2.216 & $0.896-5.483$ \\
\hline Age & 0.022 & 0.017 & 1.683 & 0.195 & 1.022 & $0.989-1.056$ \\
\hline Neutrophil percentage & 0.107 & 0.044 & 5.843 & 0.016 & 1.113 & $1.020-1.213$ \\
\hline NMR & 0.105 & 0.052 & 3.997 & 0.046 & 1.110 & $1.002-1.230$ \\
\hline NLR & -0.050 & 0.117 & 0.187 & 0.666 & 0.951 & $0.756-1.195$ \\
\hline Chest CT with ground glass change & -0.703 & 0.480 & 2.145 & 0.143 & 0.495 & $0.193-1.268$ \\
\hline Hypertension & 0.065 & 0.590 & 0.012 & 0.912 & 1.068 & $0.336-3.392$ \\
\hline Cardiovascular disease & -0.958 & 0.914 & 1.100 & 0.294 & 0.384 & $0.064-2.300$ \\
\hline Multivariate analysis was carried out using a logistic regression model. & & \\
\hline $\begin{array}{l}\text { Abbreviation: Cl, confidence interval; NMR, neutrophil/ monocyte ratio; NLR, neutrophil/ lymphocyte } \\
\text { ratio; }\end{array}$ & & & & & \\
\hline P<0.05 was considered statistically significant. & & & & & \\
\hline
\end{tabular}

Table 5

Comparison of three predictors for predicting the severity of COVID-19

\begin{tabular}{|c|c|c|c|c|c|c|c|}
\hline virables & AUC & SE & $95 \% \mathrm{Cl}$ & Cutoff & Sensitivity & Specificity & $\mathbf{P}$ \\
\hline Neutrophil percentage & 0.842 & 0.031 & $\begin{array}{l}0.782- \\
0.902\end{array}$ & $49.72 \%$ & $92.5 \%$ & $57.2 \%$ & $\begin{array}{l}< \\
0.001\end{array}$ \\
\hline NMR & 0.790 & 0.041 & $\begin{array}{l}0.710- \\
0.871\end{array}$ & $45.29 \%$ & $57.5 \%$ & $87.8 \%$ & $\begin{array}{l}<.001 \\
0.001\end{array}$ \\
\hline $\begin{array}{l}\text { Neutrophil percentage } \\
\text { combined NMR }\end{array}$ & 0.851 & 0.031 & $\begin{array}{l}0.790- \\
0.911\end{array}$ & $53.61 \%$ & $72.5 \%$ & $81.8 \%$ & $\begin{array}{l}< \\
0.001\end{array}$ \\
\hline \multicolumn{8}{|c|}{$\begin{array}{l}\text { Abbreviations: AUC: Area under curve; SE: Standard error; Cl: Confidential interval; NMR, Neutrophil/ } \\
\text { monocyte ratio; a: Combination of Neutrophil percentage and NMR was used to establish the logistic } \\
\text { regression model to obtain the prediction probability. }\end{array}$} \\
\hline
\end{tabular}

Abbreviations: ROC, receiver operating characteristics; NMR, neutrophil/ monocyte ratio.

ROCs of neutrophil percentage, NMR and combination of them for the predictors of severity of COVID-19 patients.

\section{Discussion}


To date, although the relationship between blood test parameters and COVID-19 has been repeatedly addressed, but the role of neutrophil percentage, NMR in the severity of COVID-19 has not been elaborated yet. The important finding of the study was that neutrophil percentage and NMR might act as independent risk factors in the severity of COVID-19.

Previous studies have shown that SARS-CoV-2 could contribute to hyperinflammatory response which was the main reason of the severity and death of COVID-19 patients $[15,19]$. Traditional systemic inflammatory is triggered by white blood cell which comprises of neutrophils, lymphocytes, monocytes, and immature cells[20]. Neutrophils are the most abundant leukocytes in blood circulation which are the first line of host defense against pathogens [21,22]. It was reported that humans produced 1 billion neutrophils per day per kilogram of body weigh whereas increased to 10 billion when infected [21]. In vivo, the release of danger signals recruit the neutrophils to the site of tissue necrosis [23], then activated neutrophils through releasing preformed mediators, recognizing foreign nucleic acids, extruding neutrophil extracellular traps (NETs), presenting antigens to memory CD4 T cells, producing a variety of cytokines to regulate innate and adaptive immune responses, and to some degree, neutrophils could also lead to tissue necrosis[24-28]. Neutrophils were confirmed having influence on not only infectious and autoimmune diseases but hematopoiesis, angiogenesis and cancer growth [25, 28]. The effect of neutrophils in viral infections remains ill defined, research has showed that neutrophils were the predominant cells in virus-induced lung infection and could control the replication and transmission of virus[29, 30]. In addition, neutrophils played important role in COVID-19 [17].

Neutrophil percentage usually act as the index of inflammation and increases in infected diseases [16]. In our study, univariate regression analysis showed that neutrophil percentage was the independent risk factor in the severity of COVID-19 and the AUC was 0.842 which suggested the good predictive value in the severity of COVID-19. The optimal threshold at $49.7 \%$ for neutrophil percentage signified a possibility of clinical symptoms changing from non-severity to severity with high sensitivity of 92.5 percent. Zhang et al. found higher neutrophil percentage has been reported to be related with the severity of COVID19[31], consistent with our study, although further research hasn't been explored.

The source of monocytes is bone marrow which drives from progenitor cells. Monocytes have the ability of phagocytic activity and can differentiate into antigen-presenting cells which contribute to the participation of innate and adaptive immune responses[32]. After migrating from blood to inflammatory sites, response is different whether monocytes differentiate into macrophages or myeloid dendritic cells[33, 34]. Activated monocytes release inflammatory cytokines to fight for infection, and the overexpression of cytokines is closely related with mortality, nevertheless, immunological paralysis characterized by monocyte deactivation can also explain for the poor clinical outcomes of sepsis[35, 36]. Recent study suggested that bronchoalveolar fluid were enriched in CCL2 and CCL7 in patients with severe COVID-19,which were the recruitment of CC-chemokine receptor 2-positive monocytes[37]. Singlecell RNA sequencing analysis also showed that mononuclear phagocyte comprising of depletion of tissue-resident alveolar macrophages and monocyte-derived macrophages was higher in severe COVID19 than that of mild or healthy controls [38]. 
These peripheral blood inflammatory cells are often studied together, NLR and NMR are easily calculated and serve as systemic inflammation biomarkers $[11,39]$. NLR has been studied in the severity and prognosis of COVID-19 [12-14, 18, 40], in our study, NLR was also higher in severe COVID-19. According to Fang[11], segmented NMR can act as an immune dysfunction score to predict the 28-day mortality of patients with sepsis. In present study, levels of NMR were significantly higher in severe COVID-19 than non-severe patients, which implied that NMR might be a potential serum marker for severity of COVID-19. In addition, the logistic regression analysis showed that NMR was correlated with the severity of disease and ROC analysis also suggested that NMR was a valuable predictor.

A combination of different texts can improve the sensitivity of single test, we combined NMR with neutrophil percentage and proved a sensitivity of 72.5 percent, a specificity of 81.8 percent and AUC 0.851 in recognizing the severity of COVID-19.

This study has several limitations. First, the enrolled number of patients is small which may limit the conclusions of the study. For example, several parameters at admission are related to severity of the disease in univariate regression analysis, while only neutrophil percentage and NMR make sense in the multivariate analysis. In the future research, these indicators also need closer attention. Second, disease is a process of deterioration, the indexes at admission can't reflect the changes in diseases.

\section{Conclusions}

In summary, this retrospective cohort study revealed that the neutrophil percentage and NMR are independent risk factors for the severity of COVID-19. Further researches are needed to enlarge the sample size and assess dynamically to confirm these results.

\section{List of abbreviations}

COVID-19: coronavirus disease 2019

SARS-CoV-2: severe acute respiratory syndrome coronavirus 2

NMR: neutrophil-to-monocyte ratio

NLR: neutrophil-to-lymphocyte ratio

CT: computed tomography

AUCs: Areas under the curve

Cls: confidence intervals

OR: odds ratio

ROC: Receiver operating characteristics 
NETs: neutrophil extracellular traps

\section{Declarations}

\section{Competing interests}

The authors declare that they have no competing interests.

\section{Funding}

This study was funded by Emergency Project of Prevention and Control for COVID-19 of Central South University: 160260005.

\section{Author contributions}

FP and SL are joint first authors. YZ and SW contributed to the study design, implementation, manuscript discussion and critical revision. FP, SL, CW, and BY collected and interpreted the data. All authors read and approved the final manuscript.

\section{Acknowledgments}

Not applicable.

\section{References}

1. Coronaviridae Study Group of the International Committee on Taxonomy of V. The species Severe acute respiratory syndrome-related coronavirus: classifying 2019-nCoV and naming it SARS-CoV-2. Nat Microbiol. 2020;5(4):536-44.

2. Lu H, Stratton CW, Tang YW. Outbreak of pneumonia of unknown etiology in Wuhan, China: The mystery and the miracle. J Med Virol. 2020;92(4):401-2.

3. Huang C, Wang Y, Li X, Ren L, Zhao J, Hu Y, Zhang L, Fan G, Xu J, Gu X, et al. Clinical features of patients infected with 2019 novel coronavirus in Wuhan, China. Lancet. 2020;395(10223):497-506.

4. Lu R, Zhao X, Li J, Niu P, Yang B, Wu H, Wang W, Song H, Huang B, Zhu N, et al. Genomic characterisation and epidemiology of 2019 novel coronavirus: implications for virus origins and receptor binding. Lancet. 2020;395(10224):565-74.

5. Rothe C, Schunk M, Sothmann P, Bretzel G, Froeschl G, Wallrauch C, Zimmer T, Thiel V, Janke C, Guggemos W, et al. Transmission of 2019-nCoV Infection from an Asymptomatic Contact in Germany. N Engl J Med. 2020;382(10):970-1.

6. National Health Commission of the People's Republic of China. Update on the COVID-19 outbreak as of July 31. 2020. Available at: http://www.nhc.gov.cn/wjw/index_gzbd.shtml. Accessed 31 July 2020. 
7. World Health Organization. WHO Director-General's opening remarks at the media briefing on COVID19. 2020. Available at: https://www.who.int/dg/speeches/detail/who-director-general-s-openingremarks-at-the-media-briefing-on-covid-19. Accessed 1 August 2020.

8. Li Q, Guan X, Wu P, Wang X, Zhou L, Tong Y, Ren R, Leung KSM, Lau EHY, Wong JY, et al. Early Transmission Dynamics in Wuhan, China, of Novel Coronavirus-Infected Pneumonia. N Engl J Med. 2020;382(13):1199-207.

9. Qin C, Zhou L, Hu Z, Zhang S, Yang S, Tao Y, Xie C, Ma K, Shang K, Wang W, et al: Dysregulation of immune response in patients with COVID-19 in Wuhan, China. Clin Infect Dis 2020.

10. Zhu N, Zhang D, Wang W, Li X, Yang B, Song J, Zhao X, Huang B, Shi W, Lu R, et al. A Novel Coronavirus from Patients with Pneumonia in China, 2019. N Engl J Med. 2020;382(8):727-33.

11. Fang WF, Chen YM, Wang YH, Huang CH, Hung KY, Fang YT, Chang YC, Lin CY, Chang YT, Chen HC, et al. Incorporation of dynamic segmented neutrophil-to-monocyte ratio with leukocyte count for sepsis risk stratification. Sci Rep. 2019;9(1):19756.

12. Lagunas-Rangel FA. Neutrophil-to-lymphocyte ratio and lymphocyte-to-C-reactive protein ratio in patients with severe coronavirus disease 2019 (COVID-19): A meta-analysis. J Med Virol 2020.

13. Liu Y, Du X, Chen J, Jin Y, Peng L, Wang HHX, Luo M, Chen L, Zhao Y. Neutrophil-to-lymphocyte ratio as an independent risk factor for mortality in hospitalized patients with COVID-19. J Infect 2020.

14. Lu G, Wang J. Dynamic changes in routine blood parameters of a severe COVID-19 case. Clin Chim Acta. 2020;508:98-102.

15. Merad M, Martin JC. Pathological inflammation in patients with COVID-19: a key role for monocytes and macrophages. Nat Rev Immunol. 2020;20(6):355-62.

16. Sun $Y$, Jiang $L$, Shao X. Predictive value of procalcitonin for diagnosis of infections in patients with chronic kidney disease: a comparison with traditional inflammatory markers C-reactive protein, white blood cell count, and neutrophil percentage. Int Urol Nephrol. 2017;49(12):2205-16.

17. Tomar B, Anders HJ, Desai J, Mulay SR. Neutrophils and Neutrophil Extracellular Traps Drive Necroinflammation in COVID-19. Cells 2020, 9(6).

18. Yang AP, Liu JP, Tao WQ, Li HM. The diagnostic and predictive role of NLR, d-NLR and PLR in COVID19 patients. Int Immunopharmacol. 2020;84:106504.

19. Mehta P, McAuley DF, Brown M, Sanchez E, Tattersall RS, Manson JJ. Hlh Across Speciality Collaboration UK: COVID-19: consider cytokine storm syndromes and immunosuppression. Lancet. 2020;395(10229):1033-4.

20. Dellinger RP, Levy MM, Rhodes A, Annane D, Gerlach H, Opal SM, Sevransky JE, Sprung CL, Douglas IS, Jaeschke R, et al. Surviving sepsis campaign: international guidelines for management of severe sepsis and septic shock: 2012. Crit Care Med. 2013;41(2):580-637.

21. Ley K, Hoffman HM, Kubes P, Cassatella MA, Zychlinsky A, Hedrick CC, Catz SD. Neutrophils: New insights and open questions. Sci Immuno/ 2018, 3(30). 
22. Kuwabara WMT, Andrade-Silva J, Pereira JNB, Scialfa JH, Cipolla-Neto J. Neutrophil activation causes tumor regression in Walker 256 tumor-bearing rats. Sci Rep. 2019;9(1):16524.

23. McDonald B, Pittman K, Menezes GB, Hirota SA, Slaba I, Waterhouse CC, Beck PL, Muruve DA, Kubes P. Intravascular danger signals guide neutrophils to sites of sterile inflammation. Science. 2010;330(6002):362-6.

24. Gupta S, Kaplan MJ. The role of neutrophils and NETosis in autoimmune and renal diseases. Nat Rev Nephrol. 2016;12(7):402-13.

25. Mantovani A, Cassatella MA, Costantini C, Jaillon S. Neutrophils in the activation and regulation of innate and adaptive immunity. Nat Rev Immunol. 2011;11(8):519-31.

26. Tamassia N, Bazzoni F, Le Moigne V, Calzetti F, Masala C, Grisendi G, Bussmeyer U, Scutera S, De Gironcoli M, Costantini C, et al. IFN-beta expression is directly activated in human neutrophils transfected with plasmid DNA and is further increased via TLR-4-mediated signaling. J Immunol. 2012;189(3):1500-9.

27. Vono M, Lin A, Norrby-Teglund A, Koup RA, Liang F, Lore K. Neutrophils acquire the capacity for antigen presentation to memory CD4(+) T cells in vitro and ex vivo. Blood. 2017;129(14):1991-2001.

28. Tecchio C, Micheletti A, Cassatella MA. Neutrophil-derived cytokines: facts beyond expression. Front Immunol. 2014;5:508.

29. Tumpey TM, Garcia-Sastre A, Taubenberger JK, Palese P, Swayne DE, Pantin-Jackwood MJ, SchultzCherry S, Solorzano A, Van Rooijen N, Katz JM, et al. Pathogenicity of influenza viruses with genes from the 1918 pandemic virus: functional roles of alveolar macrophages and neutrophils in limiting virus replication and mortality in mice. J Virol. 2005;79(23):14933-44.

30. Tate MD, Brooks AG, Reading PC. The role of neutrophils in the upper and lower respiratory tract during influenza virus infection of mice. Respir Res. 2008;9:57.

31. Zhang G, Zhang J, Wang B, Zhu X, Wang Q, Qiu S. Analysis of clinical characteristics and laboratory findings of 95 cases of 2019 novel coronavirus pneumonia in Wuhan, China: a retrospective analysis. Respir Res. 2020;21(1):74.

32. Imhof BA, Aurrand-Lions M. Adhesion mechanisms regulating the migration of monocytes. Nat Rev Immunol. 2004;4(6):432-44.

33. Steinman RM. The dendritic cell system and its role in immunogenicity. Annu Rev Immunol. 1991;9:271-96.

34. Warren MK, Vogel SN. Bone marrow-derived macrophages: development and regulation of differentiation markers by colony-stimulating factor and interferons. J Immunol. 1985;134(2):982-9.

35. Pinsky MR, Vincent JL, Deviere J, Alegre M, Kahn RJ, Dupont E. Serum cytokine levels in human septic shock. Relation to multiple-system organ failure and mortality. Chest. 1993;103(2):565-75.

36. Volk HD, Reinke P, Krausch D, Zuckermann H, Asadullah K, Muller JM, Docke WD, Kox WJ. Monocyte deactivation-rationale for a new therapeutic strategy in sepsis. Intensive Care Med. 1996;22(Suppl 4):474-81. 
37. Wood GS, Freudenthal PS, Edinger A, Steinman RM, Warnke RA. CD45 epitope mapping of human CD1a + dendritic cells and peripheral blood dendritic cells. Am J Pathol. 1991;138(6):1451-9.

38. Steinman RM, Young JW. Signals arising from antigen-presenting cells. Curr Opin Immunol. 1991;3(3):361-72.

39. Saricam G. Relationship between migraine headache and hematological parameters. Acta Neurol Belg 2020.

40. Zeng F, Li L, Zeng J, Deng Y, Huang H, Chen B, Deng G. Can we predict the severity of coronavirus disease 2019 with a routine blood test? Pol Arch Intern Med. 2020;130(5):400-6.

\section{Figures}
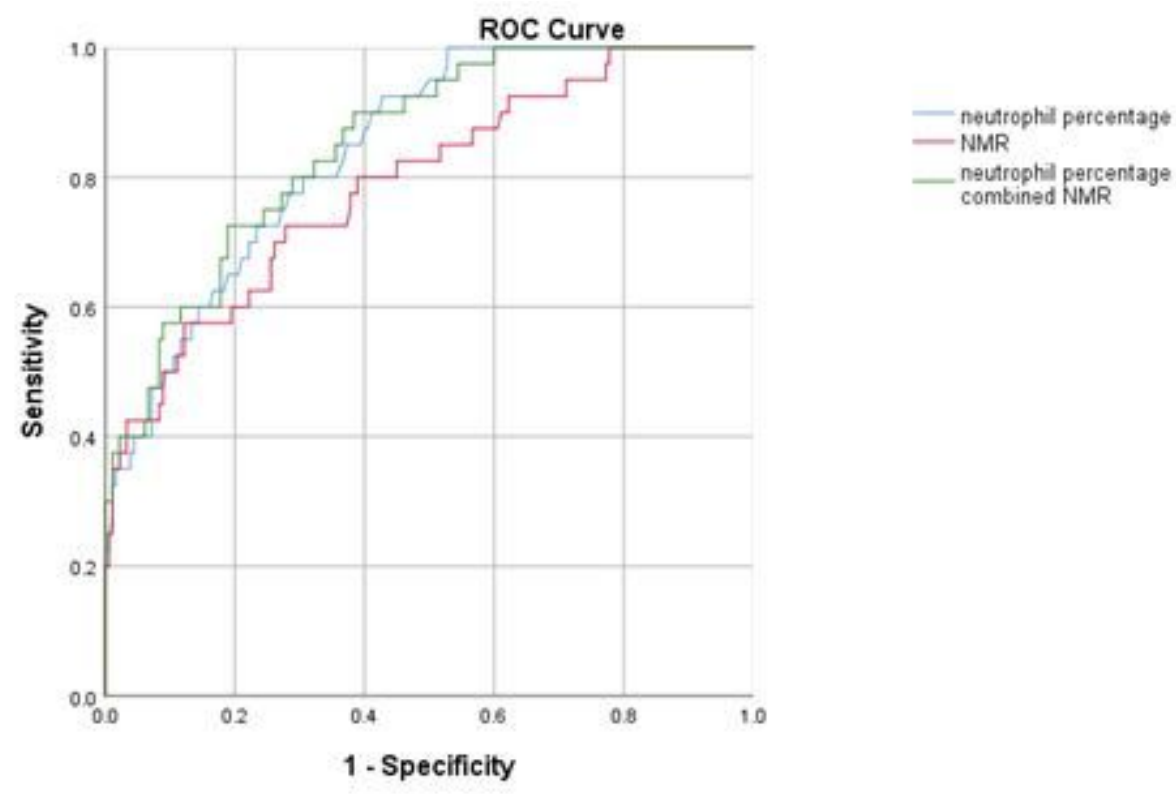

Figure 1

ROC curves of three methods for predicting the severity of COVID-19 Abbreviations: ROC, receiver operating characteristics; NMR, neutrophil/ monocyte ratio. ROCs of neutrophil percentage, NMR and combination of them for the predictors of severity of COVID-19 patients. 